\section{Eating Habits and Knowledge of Nutrition in Older Adults: A Comparison of Gardeners and Nongardeners}

\author{
Amy McFarland ${ }^{1,4}$, Tina M. Waliczek ${ }^{2,5,6}$, Jayne M. Zajicek ${ }^{3,5}$, and \\ R. Dan Lineberger ${ }^{3,5}$
}

ADDitionAl INDEX wORDs. food-frequency questionnaire, food choices, food attitudes, fruit and vegetable consumption, horticultural therapy

Summary. A survey was used to investigate gardeners' and nongardeners' nutritional attitudes, fruit and vegetable consumption, and nutritional knowledge. The survey was posted for $\mathbf{4}$ months on one of the largest online resources for Master Gardeners. During the 4 months, 402 responses were gathered. Additionally, identical "paper/pencil" format surveys were distributed to garden, church, and social and community groups with $\approx \mathbf{4 0 0}$ responses received. In each group of participants, respondents differentiated themselves as gardeners or nongardeners by responding positively or negatively to the survey question, "do you garden?" No statistically significant relationships were found relating fruit and vegetable consumption to either income level or educational attainment status in the overall sample. Results indicated statistically significant differences in comparisons between gardeners and nongardeners with regards to nutritional attitudes and their consumption of fruit and vegetables where gardeners had more positive nutritional attitude scores and increased consumption of fruit and vegetables. However, no statistically significant differences were found between gardeners' and nongardeners' nutritional knowledge.

$\mathrm{D}$ espite numerous national campaigns, the consumption of fruit and vegetables in the U.S. population remains at lower than recommended levels (Blanck et al., 2008; Dehghan et al., 201 1; Demydas, 2011 ). It is estimated that over $75 \%$ of the adult population does not consume the minimum recommendation of at least five daily servings of fruit and vegetables.

As the older adult population in the United States continues to grow, so does concern for the health of this population (Arias, 2007). Older adults have an increased rate of susceptibility to chronic disease and disability and increased cost for healthcare (Arterburn et al., 2004; Centers for Disease Control and Prevention, 2007). Poor nutrition is one factor that has been linked to the rising cost of healthcare and the consumption of fruit and vegetables has consistently been linked to improved health (Nestle, 2007;

${ }^{1}$ Farmingdale State College, Farmingdale, NY 11735 ${ }^{2}$ Department of Agriculture, Texas State University, San Marcos, TX 78666

${ }^{3}$ Department of Horticultural Sciences, Texas A\&M University, College Station, TX 77843

${ }^{4}$ Visiting Assistant Professor

${ }^{5}$ Professor of Horticulture

${ }^{6}$ Corresponding author. E-mail: tcl0@txstate.edu.
Schlettwein-Gsell, 1992). Research on older adults consistently shows that older populations do not consume the proper numbers of servings of fruit and vegetables on a daily basis (Bowman, 2007; Prochaska et al., 2005; Sommerfeld et al., 2010a; Vitolins et al., 2007). Bisogni et al. (2002) reported that older adults who were born during World War II consumed fewer fruit and vegetables due to the rationing of nonbasic caloric needs experienced during this time period. This dietary restriction may have carried over to the children of this age group and, therefore, potentially persists today. To exacerbate the problem of poor nutritional intake, older adults suffer from decreased nutrient absorption rates, indicating that those nutrients that are consumed may be used less efficiently by older adults (Vitolins et al., 2007).

Gardening has been shown to have an impact on food choices for both children and adults through improving the access to and increasing the preference for fruit and vegetables (Devine et al., 1999; Heim et al., 2009; Koch et al., 2006; Mummery et al., 2007; Sommerfeld et al., 2010a). Particularly, past research has suggested that gardening may have an impact on food choices for adults aged 50 years or older (Sommerfeld et al., 2010a). Researchers suggested that it is through the increased personal connection to food through the hands-on activities gardening provides that this improvement in dietary consumption occurs (Heim et al., 2009). Gardening may be an effective tool for engaging the older population with food and nutrition issues as it is a favorite physical leisure time activity for older adults (AshtonShaeffer and Constant, 2005; Bertera, 2003). In fact, in a study of all adults, gardening was considered one of the top two leisure-time physical activities preferred across all ethnicities (Crespo et al., 1996).

Participation in gardening programs also has an impact on the nutritional knowledge and attitudes of individuals (Hackman and Wagner, 1990; Koch et al., 2006; Libman, 2007). However, research that links nutritional knowledge with health has reported mixed results. Wardle et al. (2000) reported that improved nutritional knowledge was related to greater consumption of fruit and vegetables. However, other studies reported factors such as food availability and cultural, economic, and educational factors were as important, if not more so, when compared with nutritional knowledge on actual food choices (Dallongeville et al., 2000; O'Brien and Davies, 2007; Shepherd and Towler, 2007).

The goal of this study was to compare older gardeners' and nongardeners' nutritional attitudes, eating habits (with regards to fruit and vegetable consumption and the consumption of salty and sweet snacks), and their knowledge of nutrition (specifically, fat, fiber, and salt).

\section{Materials and methods}

InSTRUMENTATION. The survey instrumentation consisted of a total of 41 questions including sections concerning nutritional attitudes, food frequency, and nutritional knowledge. Each section was reviewed by a total of four horticultural and nutrition researchers to ensure validity. This preliminary review team verified the appropriateness of nutrition, gardening, and fruit and vegetable questions. Questions were modified based upon feedback from each of these preliminary reviewers. 
The nutritional attitudes section of the survey included 10 statements rated on a three-point Likert-type scale (Likert, 1967) including "agree," "I don't know," and "disagree." This section asked questions like, "eating healthy makes me feel better," and "lots of things get in the way of my eating a healthier diet." These statements were modeled from previous studies (Sjoberg et al., 2004). This section of the survey was scored with the more positive response scoring three points, "I don't know" scoring two points, and the least positive response scoring one point. Cronbach's $\alpha$ analysis for this section of the survey indicated an internal reliability coefficient of $\alpha=0.53$. An $\alpha$ greater than 0.50 is considered acceptable for short instruments of 10-15 items and for health-related inventories (Bowling, 1997; Kehoe, 1995).

The second section of the survey included a food-frequency questionnaire with statements regarding how many times during the past month the participant consumed each of 16 different fruit and vegetables. This section was modeled after the questionnaire developed by Sommerfeld et al. (2010a), but answer responses were expanded as per their study recommendations. In Sommerfeld et al. (2010a), it was determined that participants needed answer responses of greater than five times per month to identify sufficient variation in data. Therefore, the possible responses allowed in this study included " 0 to 5 " (one point), "6 to 10" (two points), "1l to 15 " (three points), "16 to 20 " (four points), " 21 to 25 " (five points), " 26 to 30 " (six points), and " $>30$ " (seven points). This expanded range allowed greater variation in the data to help identify clear differences between participants.

Participants were asked to consider their food choices for the previous month to allow for variation in vegetable and fruit choices from day to day. The score for each fruit and vegetable was summed to calculate an overall fruit and vegetable consumption score which could potentially range from 16 to 112. Statements pertaining to nonfruit and vegetable food choices were also included such as "meats/poultry/fish," "eggs," "milk products," "sweets," "salty snack foods," and "sweet drinks." The possible responses to these statements were the same as those for specific fruit and vegetables. This section was scored such that between 1 and 7 points were possible with the fewer frequency categories received fewer points and higher frequency categories receiving more points. This section of the instrument had a Cronbach's reliability coefficient of $\alpha=0.87$.

The third section of the instrument measured participants' nutritional knowledge by asking them to identify between two food choices. There were 15 questions included on this section with five in each of the following categories: fat, fiber, and salt. For example, participants were asked, "Please mark the food from each pair that you think is lower in fat": "spaghetti with red sauce or ham and cheese hot dish," "cheeseburger or turkey sandwich," "chicken and rice soup or cream of chicken soup." Similar questions were asked with regards to pairings of food in the fiber and salt categories. This section was scored such that the correct response scored two points for a possible range of scores from 15 to 30 points. This section of the survey had a Cronbach's reliability coefficient of $\alpha=0.57$.

Demographic information was also gathered including gender, ethnicity, age, education, income, living situation, and working status of the participant. These statements were used to investigate differences in fruit and vegetable consumption based on demographic categories in addition to comparisons made based on whether the participant self-identified as a gardener.

SAMPLE POPUlation. The target population in this study was adults aged 50 years or older. This age was selected as the definition of an "older adult" because it is the standardized age for member acceptance in the AARP [formerly the American Association of Retired Persons (AARP, 2010; Sommerfeld et al., 2010b)]. After Internal Review Board approval, the sample was drawn from two sources. About half of the sample population responded to the survey online where it was posted for 4 months, July through October, on one of the largest online resources for Master Gardeners. The survey was left open for 4 months to ensure a large number of responses were received from which to tabulate data.
Respondents self-selected themselves for inclusion in the study by visiting the webpage and choosing to answer the survey after reviewing an informed consent page. The survey was not advertised in any manner other than the link to it on the webpage. The incentive for responding to the survey on the Internet was a packet of wildflower seed delivered to each participant in the mail. During the 4 months, 402 usable responses were gathered. Once each participant completed the survey, responses were automatically downloaded onto a computer spreadsheet. Survey respondents provided their names and addresses to have the wildflower seed mailed to them. This record of participants ensured each respondent only provided one survey response and the identifying information was removed from the database before data analysis to ensure confidentiality.

Additionally, during the same 4 months of Internet survey collection, identical "paper/pencil" format surveys were distributed to garden, church, and social and community service groups within parts of central United States (primarily Texas and Kansas) and especially allowed nongardeners and those without Internet access the opportunity to participate in the study. Groups were chosen for participation based on their ease of accessibility, interest level in participation, and willingness to allow time for respondents to answer during meeting times. Four hundred usable surveys were received from this group. Each participant responding to the "paper/ pencil" format survey was given a dollar as an incentive. In each group of participants, respondents differentiated themselves as gardeners or nongardeners by responding positively or negatively to the survey question, "do you garden?" Gardening was not defined and could include any of ornamental gardening, food gardening, and container gardening.

Data Analysis. Data collected was analyzed using SPSS ${ }^{\circledR}$ (version 17.0; IBM Corp., Armonk, NY). Statistical procedures included frequencies and analysis of variance (ANOVA) tests to determine differences between fruit and vegetable consumption in gardeners and nongardeners and to determine any demographic influences. 


\section{Results}

Because the samples were drawn from different sources, and had the potential to bias the data based on the respondent having access to a computer and an Internet connection, the samples were compared to see if they differed demographically. Statistically significant differences were found on variables including the income, age, and education level of those responding on the Internet vs. those responding on the traditional paper survey. The Internet group had obtained a higher level of education, was somewhat younger, and had higher incomes. Because of the confounding differences within the sample, a subsample of 443 of the original 802 respondents was drawn to overcome any initial differences within the group. The subsample was drawn by sorting and matching the gardeners and nongardeners on the variables of income, age, and education. To sort and match gardeners and nongardeners, data were initially analyzed to report and list median values for both gardeners and nongardeners for the variables of interest. From this information, researchers could observe where the data for each group overlapped, and select respondents within the suitable range of values for the variables of interest. Additionally, outlier data were removed from within the sample. This sorting of data provided a sample of participants who were similar on these potentially confounding variables of income, age, and education.

The overall subsample included comparatively even distributions of gardeners $(49.7 \%)$ to nongardeners (50.3\%), with 220 total respondents being gardeners and 223 nongardener respondents.

Overall sample. The strength of association among the variables of nutritional knowledge score, nutritional attitudes score, total sweets score, total fruit and vegetables score, milk products score, eggs score, salty snacks score, and meat/poultry/fish score were measured using Pearson's product-moment correlations. Statistically significant correlations were found between nutritional knowledge score and the following variables: nutritional attitudes score, total fruit and vegetables score, milk products score, meat/poultry/fish score, and total sweets score. This indicated that as nutritional knowledge increased, so did nutritional attitudes, total fruit and vegetable consumption, and the consumption of milk products, meat/poultry/fish, and sweets. However, consumption of salty snacks and eggs did not increase as nutritional knowledge increased (Table 1).

The relationship between the consumption of each category of food and educational attainment status and income level was also analyzed since, as previously reported, these categories can have an impact on the consumption

Table 1. Correlation matrix indicating the strength of association among the variables of nutritional knowledge score, nutritional attitudes score, total sweets score, total fruit and vegetables score, milk products score, eggs score, salty snacks score, and meat/poultry/fish score in the study of eating habits and knowledge of nutrition in older adults comparing gardeners and nongardeners.

\begin{tabular}{|c|c|c|c|c|c|c|c|c|}
\hline Variable & & $\begin{array}{l}\text { Nutritional } \\
\text { attitudes } \\
\text { score }^{\mathrm{z}}\end{array}$ & $\begin{array}{c}\text { Total } \\
\text { sweets } \\
\text { score }\end{array}$ & $\begin{array}{c}\text { Total } \\
\text { fruit and } \\
\text { vegetables } \\
\text { score }\end{array}$ & $\begin{array}{l}\text { Milk } \\
\text { products } \\
\text { score }\end{array}$ & $\begin{array}{l}\text { Eggs } \\
\text { score }\end{array}$ & $\begin{array}{l}\text { Salty } \\
\text { snacks } \\
\text { score }\end{array}$ & $\begin{array}{l}\text { Meat/ } \\
\text { poultry/ } \\
\text { fish score }\end{array}$ \\
\hline score $^{y}$ & $P$ & 0.01 & 0.01 & 0.01 & 0.02 & 0.29 & 0.37 & 0.01 \\
\hline & $\mathrm{N}^{\mathrm{w}}$ & 401 & 401 & 401 & 382 & 380 & 378 & 383 \\
\hline \multirow[t]{2}{*}{ Nutritional attitudes score } & $\mathrm{R}$ & & 0.05 & $0.26^{*}$ & $0.11^{*}$ & 0.01 & -0.09 & $0.20^{*}$ \\
\hline & $\mathrm{N}$ & & 401 & 401 & 382 & 380 & 378 & 383 \\
\hline \multirow[t]{3}{*}{ Total sweets score } & $\mathrm{R}$ & & & $0.32 *$ & $0.26^{*}$ & 0.31 * & $0.78^{*}$ & $0.37^{*}$ \\
\hline & $P$ & & & 0.01 & 0.01 & 0.01 & 0.01 & 0.01 \\
\hline & $\mathrm{N}$ & & & 401 & 382 & 380 & 378 & 383 \\
\hline \multirow{2}{*}{$\begin{array}{l}\text { Total fruit and vegetables } \\
\text { score }\end{array}$} & $\mathrm{R}$ & & & & $0.38^{*}$ & $0.27^{*}$ & $0.15^{*}$ & $0.49^{*}$ \\
\hline & $P$ & & & & 0.01 & 0.01 & 0.01 & 0.01 \\
\hline \multirow[t]{3}{*}{ Eggs score } & $\mathrm{R}$ & & & & & & 0.30 * & $0.33^{*}$ \\
\hline & $P$ & & & & & & 0.01 & 0.01 \\
\hline & $\mathrm{N}$ & & & & & & 372 & 376 \\
\hline \multirow[t]{3}{*}{ Salty snacks score } & $\mathrm{R}$ & & & & & & & $0.25^{*}$ \\
\hline & $P$ & & & & & & & 0.01 \\
\hline & $\mathrm{N}$ & & & & & & & 375 \\
\hline
\end{tabular}

${ }^{2}$ Calculated by summing scores to individual statements on a nutritional attitude instrument. Higher scores indicated more nutritionally focused attitudes and lower scores indicated less nutritionally focused attitudes.

${ }^{y}$ Calculated by summing scores to individual questions regarding nutritional knowledge. Higher scores indicated more nutritional knowledge and lower scores indicated less nutritional knowledge.

'Pearson's product-moment correlation.

"N (sample size) varies due to nonresponse in different categories.

* Statistically significant at the 0.05 level. 
of healthy foods (Dallongeville et al., 2000; O'Brien and Davies, 2007; Shepherd and Towler, 2007). In the overall sample, a statistically significant relationship was identified between income level and nutritional attitudes score, nutritional knowledge score, meat/poultry/fish score, milk products score, salty snacks score, and total sweets score. No statistically significant relationship was found between income level and total fruit and vegetables score or eggs score.

Statistically significant relationships were identified between educational attainment status and nutritional attitudes score, nutritional knowledge score, meat/poultry/fish score, milk products score, and total sweets score. However, no statistically significant relationships were identified between educational attainment status and total fruit and vegetables score, eggs score, or salty snacks score (Table 2 ). This indicated that higher income levels and higher educational levels were related to higher levels of consumption in several categories, but not the category of fruit and vegetable consumption, which diverges from previous research (Dallongeville et al., 2000; O'Brien and Davies, 2007; Shepherd and Towler, 2007). In this sample, since gardeners and nongardeners were matched on demographic variables, as near of equal numbers of gardeners and nongardeners were included in each category of income as possible. However, more gardeners were in the lowest two income categories when compared with nongardeners.

GARDENERS vs. NONGARDENERS. An ANOVA comparison results indicated statistically significant differences in comparisons of the nutritional attitudes of gardeners and nongardeners with gardeners scoring statistically significantly higher when compared with nongardeners (Table 3). This indicated that gardeners were more likely to report positive nutritional habits such as finding value in taking time to prepare nutritious meals and reporting feeling better when nutritious foods were consumed when compared with nongardeners. This finding supports previous research that indicated that nutritional attitudes in older adults improved as a result of a gardening program (Hackman and Wagner, 1990).

An ANOVA comparison between gardeners and nongardeners with regards to fruit and vegetable consumption was also analyzed. Results of this analysis indicated that gardeners consumed more servings of fruit and vegetables each month when compared with nongardeners (Table 4). Gardeners, on average, scored 32.75 points on this section of the questionnaire and nongardeners, on average, scored 29.95 points on this section of the questionnaire. A score of 32.75 points results in between 196.5 and 327.5 monthly servings of fruit and vegetables. A score of 29.95 results in between 179.7 and 299.5 monthly servings of fruit and vegetables. This is a difference of between $\approx 17$ and 28 servings of fruit and vegetables each month or approximately one-half to one serving per day.

A comparison of the differences in consumption of individual fruit and vegetables between gardeners and nongardeners revealed the specific fruit and vegetables consumption differences that existed. Statistically significant differences were found in the individual categories of "tomato" (Solanum lycopersicum), "herbs," and "any fruit" categories with gardeners consuming more in each category (Table 4). No statistically significant differences were found in the individual categories of "peppers" (Capsicum sp.), "iceberg lettuce" (Lactuca sativa), "peas and beans" (Pisum sativum and Phaseolus sp.)," "cole crops" (Brassica sp.), "potatoes" (Solanum tuberosum), "carrots" (Daucus carota), "fresh salad greens," "sweet corn" (Zea mays), "sweet potatoes" (Ipomoea batatas), "sweet melons" (Cucumis sp.), "citrus and juices" (Citrus sp.), "bananas" (Musa paradisiaca), and "apples/pears" (Malus $\times$ domestica and Pyrus sp.). This finding merits additional research as many of the nonconsumed items are commonly grown within a typical vegetable garden. However, gardeners in this sample included those whom gardened for food or flowers, and not necessarily for both. This finding supported previous research indicating that gardeners consume a greater quantity of fruit and vegetables when compared with nongardeners (Blair

Table 2. Correlation matrix indicating the strength of association among the variables of income level, educational attainment status, nutritional knowledge score, nutritional attitudes score, total sweets score, total fruit and vegetables score, milk products score, eggs score, salty snacks score, and meat/poultry/fish score in the study of eating habits and knowledge of nutrition in older adults comparing gardeners and nongardeners.

\begin{tabular}{|c|c|c|c|c|c|c|c|c|c|}
\hline Variable & & $\begin{array}{c}\text { Nutritional } \\
\text { knowledge } \\
\text { score }^{\mathrm{z}}\end{array}$ & $\begin{array}{c}\text { Nutritional } \\
\text { attitudes } \\
\text { score }^{\mathrm{y}}\end{array}$ & $\begin{array}{c}\text { Total } \\
\text { sweets } \\
\text { score }\end{array}$ & $\begin{array}{c}\text { Total } \\
\text { fruit and } \\
\text { vegetables } \\
\text { score } \\
\end{array}$ & $\begin{array}{c}\text { Milk } \\
\text { products } \\
\text { score }\end{array}$ & $\begin{array}{l}\text { Eggs } \\
\text { score }\end{array}$ & $\begin{array}{c}\text { Salty } \\
\text { snacks } \\
\text { score }\end{array}$ & $\begin{array}{l}\text { Meat/ } \\
\text { poultry/ } \\
\text { fish score }\end{array}$ \\
\hline \multirow[t]{3}{*}{ Income level } & $r^{\mathrm{x}}$ & $0.25^{*}$ & $0.20^{*}$ & $0.16^{*}$ & -0.05 & $0.12^{*}$ & 0.01 & $0.19^{*}$ & $0.14^{*}$ \\
\hline & $P$ & 0.01 & 0.01 & 0.01 & 0.39 & 0.04 & 0.90 & 0.01 & 0.02 \\
\hline & $\mathrm{N}^{\mathrm{w}}$ & 297 & 297 & 297 & 297 & 289 & 286 & 283 & 288 \\
\hline & $\mathrm{N}$ & 386 & 386 & 386 & 386 & 372 & 369 & 367 & 372 \\
\hline
\end{tabular}

${ }^{\mathrm{z}}$ Calculated by summing scores to individual questions regarding nutritional knowledge. Higher scores indicated more nutritional knowledge and lower scores indicated less nutritional knowledge.

${ }^{y}$ Calculated by summing scores to individual statements on a nutritional attitude instrument. Higher scores indicated more nutritionally focused attitudes and lower scores indicated less nutritionally focused attitudes.

'Pearson's product-moment correlation.

${ }^{\mathrm{w}} \mathrm{N}$ (sample size) varies due to nonresponse in different categories.

* Statistically significant at the 0.05 level. 
Table 3. Analysis of variance comparisons of gardeners' and nongardeners' nutritional attitudes score in the study of eating habits and knowledge of nutrition in older adults comparing gardeners and nongardeners.

\begin{tabular}{lcccccc}
\hline $\begin{array}{l}\text { Nutrition } \\
\text { attitude score }^{\mathrm{z}}\end{array}$ & $\begin{array}{c}\text { Sample } \\
\text { size (no.) }\end{array}$ & Mean & sD & df & F & $\boldsymbol{P}$ \\
\hline Gardeners & 167 & 22.74 & 3.88 & 376 & 6.96 & $0.009^{*}$ \\
Nongardeners & 210 & 21.58 & 4.55 & & & \\
\hline
\end{tabular}

${ }^{\mathrm{z} C a l c u l a t e d ~ b y ~ s u m m i n g ~ s c o r e s ~ t o ~ i n d i v i d u a l ~ s t a t e m e n t s ~ o n ~ a ~ n u t r i t i o n a l ~ a t t i t u d e ~ i n s t r u m e n t . ~ H i g h e r ~ s c o r e s ~}$ indicated more nutritionally focused attitudes and lower scores indicated less nutritionally focused attitudes. Scores could possibly range from 10 to 30 .

* Statistically significant at the 0.05 level.

Table 4. Analysis of variance comparisons of gardeners' and nongardeners' overall fruit and vegetable consumption in the study of eating habits and knowledge of nutrition in older adults comparing gardeners and nongardeners.

\begin{tabular}{lccccccc}
\hline $\begin{array}{l}\text { Total frequency } \\
\text { of consumption } \\
\text { of fruits and }\end{array}$ & $\begin{array}{c}\text { Sample } \\
\text { size (no.) }\end{array}$ & $\begin{array}{l}\text { Mean } \\
\text { score }^{\mathbf{z}}\end{array}$ & SD & df & F & $\boldsymbol{P}$ \\
\hline $\begin{array}{l}\text { Gardeners } \\
\text { Nongardeners }\end{array}$ & 167 & 32.75 & 8.766 & 376 & 9.038 & $0.003^{*}$ \\
& 210 & 29.95 & 9.163 & & &
\end{tabular}

Total frequency of

consumption of Sample

\begin{tabular}{|c|c|c|c|c|c|c|}
\hline individual items $^{y}$ & size (no.) & Mean $^{\mathrm{y}}$ & SD & df & $\mathbf{F}$ & $P$ \\
\hline \multicolumn{7}{|l|}{ Tomatoes } \\
\hline Gardeners & 166 & 2.25 & 0.897 & 366 & 7.60 & $0.006^{*}$ \\
\hline Nongardeners & 201 & 1.95 & 0.841 & & & \\
\hline \multicolumn{7}{|l|}{ Herbs in quantity } \\
\hline Gardeners & 163 & 1.52 & 0.834 & 359 & 4.65 & 0.032 * \\
\hline Nongardeners & 197 & 1.36 & 0.682 & & & \\
\hline \multicolumn{7}{|l|}{ Any fruit } \\
\hline Gardeners & 163 & 2.85 & 0.904 & 366 & 5.16 & $0.024^{*}$ \\
\hline Nongardeners & 204 & 2.62 & 0.947 & & & \\
\hline \multicolumn{7}{|l|}{ Eggs } \\
\hline Gardeners & 164 & 1.86 & 0.790 & 364 & 0.265 & $0.003^{*}$ \\
\hline Nongardeners & 198 & 2.15 & 0.865 & & & \\
\hline \multicolumn{7}{|l|}{ Salty snacks } \\
\hline Gardeners & 164 & 2.02 & 0.893 & 360 & 5.526 & $0.017^{*}$ \\
\hline Nongardeners & 197 & 2.26 & 0.984 & & & \\
\hline
\end{tabular}

\begin{tabular}{lcccccc} 
individual items $^{\mathrm{y}}$ & size (no.) & Mean $^{\mathrm{y}}$ & SD & df & F & $P$ \\
\hline Tomatoes & & & & & & \\
$\quad$ Gardeners & 166 & 2.25 & 0.897 & 366 & 7.60 & $0.006^{*}$ \\
$\quad$ Nongardeners & 201 & 1.95 & 0.841 & & & \\
$\quad$ Herbs in quantity & & & & & & \\
$\quad$ Gardeners & 163 & 1.52 & 0.834 & 359 & 4.65 & $0.032^{*}$ \\
$\quad$ Nongardeners & 197 & 1.36 & 0.682 & & & \\
$\quad \begin{array}{l}\text { Any fruit } \\
\quad \text { Gardeners }\end{array}$ & 163 & 2.85 & 0.904 & 366 & 5.16 & $0.024^{*}$ \\
$\quad$ Nongardeners & 204 & 2.62 & 0.947 & & & \\
$\quad$ Eggs & 164 & 1.86 & 0.790 & 364 & 0.265 & $0.003^{*}$ \\
$\quad$ Gardeners & 198 & 2.15 & 0.865 & & & \\
$\quad$ Nongardeners & & & & & & \\
Salty snacks & 164 & 2.02 & 0.893 & 360 & 5.526 & $0.017^{*}$ \\
$\quad$ Gardeners & 197 & 2.26 & 0.984 & & & \\
$\quad$ Nongardeners & & & & & & \\
\hline
\end{tabular}

${ }^{z}$ Calculated by summing responses on the fruit and vegetable section of the food-frequency questionnaire where each point indicated up to five servings monthly. Scores could possibly range from 16 to 112 . Higher scores indicated more consumption of fruit and vegetables and lower scores indicated less consumption of fruit and vegetables.

Indicated by responses on individual statements on the food-frequency questionnaire where each point indicated up to five servings monthly. Scores could possibly range from 1 to 7 . Higher scores indicated more consumption of items and lower scores indicated less consumption of items.

*Statistically significant at the 0.05 level.

et al., 1991; Koch et al., 2006; Mummery et al., 2007; Sahyoun et al., 2005; Sommerfeld et al., 2010a). Unlike Sommerfeld et al. (2010a), who found that gardeners and nongardeners consumed similar quantities of fruit, this study found that gardeners did report consuming "any fruit" more frequently when compared with nongardeners.

Statistically significant differences were found in ANOVA comparisons of gardeners' and nongardeners' consumption of individual nonfruit and nonvegetable items including comparisons of eggs and salty snacks with nongardeners consuming higher quantities of each category when compared with gardeners (Table 4). No statistically significant difference was found in the categories of meat, fish, and poultry $(P=0.899)$, milk $(P=0.825)$, sweets $(P=0.659)$, and sweet drinks $(P=0.336)$.

An ANOVA was conducted comparing the nutritional knowledge scores of gardeners compared with nongardeners. No statistically significant difference was found with regards to this analysis $(P=0.070)$. This finding diverges from previous findings where gardening programs were shown to have an impact on the nutritional knowledge of participants (Hackman and Wagner, 1990; Koch et al., 2006; Libman, 2007). However, those programs tended to use nutrition curriculum in the garden. Perhaps it is the specific curriculum that improved the nutritional knowledge of participants rather than the gardening activities themselves.

\section{Discussion}

The obesity epidemic in the United States is one of the currently most discussed topics. Some research suggests that by 2030 , over $86 \%$ of adults will be overweight or obese if current eating and activity trends continue with a resulting cost of nearly $\$ 1$ trillion (Wang et al., 2008). Given this, the country is in dire need of intervention programs designed to engage people with their food choices. Gardening may be one way to interest people in activities that can introduce them to new, healthy food options and to potentially influence their attitudes toward nutrition and health.

There are a number of reasons why gardening might support a healthier lifestyle. One reason may be that gardeners have access to fruit and vegetables in areas where access to healthy foods may otherwise be limited (Hackman and Wagner, 1990; Koch et al., 2006; Libman, 2007). Another suggested reason why gardening might support healthier eating habits is because of the increased exposure to healthy foods and because new foods often need to be presented several times to become accepted (Heim et al., 2009).

This study was limited in that it was correlational in nature. As such, causality cannot be concluded. It may be that people who prefer fruit and vegetables are more likely to garden; however, this study included both people who did ornamental gardening and those who gardened for food. This research also depended on selfreports of food intake, which may result in inaccurate accounts of actual fruit and vegetable consumption. However, this research supports quasiexperimental studies using pre- and post-test designs that also recommend gardening programs as a method of improving fruit and vegetable consumption in both younger and older 
populations (Hackman and Wagner, 1990; Koch et al., 2006; Libman, 2007).

\section{Literature cited}

AARP. 2010. AARP. 7 Feb. 2012. <http://aarp.org/about-aarp/>.

Arias, E. 2007. United States life tables, 2004. Natl. Vital Stat. Rep. 56:1-6.

Arterburn, D.E., P.K. Crane, and S.D. Sullivan. 2004. The coming epidemic of obesity in elderly Americans. J. Amer. Geriatr. Soc. 52:1907-1912.

Ashton-Shaeffer, C. and A. Constant. 2005. Why do older adults garden? Act. Adaptation Aging 30:1-18.

Bertera, E.M. 2003. Physical activity and social network contacts in community dwelling older adults. Act. Adaptation Aging 27:113-127.

Bisogni, C.A., M. Connors, C.M. Devine, and J. Sobal. 2002. Who we are and what we eat: A qualitative study of identities in food choice. J. Nutr. Educ. Behav. 34: 128-139.

Blair, D., C.C. Giesecke, and S. Sherman. 1991. A dietary, social, and economic evaluation of the Philadelphia urban gardening project. J. Nutr. Educ. 23:161167.

Blanck, H.M., C. Gillespie, J.E. Kimmons, J.D. Seymour, and M.K. Serdula. 2008. Trends in fruit and vegetable consumption among U.S. men and women, 1994-2005. Prev. Chronic Dis. 5:1-10.

Bowling, A. 1997. Research methods in health. Open University Press, Buckingham, UK.

Bowman, S. 2007. Low economic status is associated with suboptimal intakes of nutritious foods by adults in the National Health and Nutrition Examination Study 1999-2002. Nutr. Res. 27:515-523.

Centers for Disease Control and Prevention. 2007. Improving the health of older Americans: A CDC priority. Chronic Dis. Notes Rpt. 18:1-7.

Crespo, C.J., S.J. Keteyian, G.W. Heath, and C.T. Sempos. 1996. Leisure-time physical activity among US adults. Arch. Intern. Med. 156:93-98.

Dallongeville, J., N. Marécaux, D. Cottel, A. Bingham, and P. Amouyel. 2000. Association between nutrition knowledge and nutritional intake in middle-aged men from northern France. Public Health Nutr. 4:27-33.

Dehghan, M., N. Akhtar-Danesh, and A.T. Merchant. 2011. Factors associated with fruit and vegetable consumption among adults. J. Hum. Nutr. Diet. 24: 128-134.

Demydas, T. 2011. Consumer segmentation based on the level and structure of fruit and vegetable intake: An empirical evidence for US adults from the National Health and Nutrition Examination Survey (NHANES) 2005-2006. Public Health Nutr. 14:1088-1095.

Devine, C.M., W.S. Wolfe, E.A. Frongillo, and C.A. Bisogni. 1999. Life-course events and experiences: Association with fruit and vegetable consumption in 3 ethnic groups. J. Amer. Dietetic Assn. 99: 309-314.

Hackman, R.M. and E.L. Wagner. 1990. The senior gardening and nutrition project: Development and transport of a dietary behavior change and health promotion program. J. Nutr. Educ. 22:262270.

Heim, S., J. Stang, and M. Ireland. 2009. A garden pilot project enhances fruit and vegetable consumption among children. J. Amer. Dietetic Assn. 109:1220-1226.

Kehoe, J. 1995. Basic item analysis for multiple-choice tests. Practical Assessment Res. Evaluation 4. 15 Aug. 2012. <http:// pareonline.net/getvn.asp? $\mathrm{v}=4 \& \mathrm{n}=10>$.

Koch, S., T.M. Waliczek, and J.M. Zajicek. 2006. The effect of a summer garden program on the nutritional knowledge, attitudes, and behaviors of children. HortTechnology 16:620-625.

Libman, K. 2007. Growing youth growing food: How vegetable gardening influences young people's food consciousness and eating habits. Appl. Environ. Educ. Commun. 6:87-95.

Likert, R. 1967. The method of constructing an attitude scale, p. 90-95. In: M. Fishbein (ed.). Readings in attitude theory and measurement. Wiley, New York.

Mummery, W.K., G. Kolt, G. Schofield, and G. McLean. 2007. Associations between physical activity and other lifestyle behaviors in older New Zealanders. J. Phys. Act. Health 4:411-422.

Nestle, M. 2007. Food politics: How the food industry influences nutrition and health. Univ. of California Press, Berkeley, CA.

O'Brien, G. and M. Davies. 2007. Nutrition knowledge and body mass index. Health Educ. Res. 22:571-575.

Prochaska, J.D., J.R. Sharkey, M.G. Ory, and J.N. Burdine. 2005. Assessing healthful eating among community dwelling rural older adults using self-reported fruit and vegetable consumption via a communitywide mail-out health status assessment. J. Nutr. Elder. 25:101-112.

Sahyoun, N.R., X.L. Zhang, and M.K. Serdula. 2005. Barriers to the consumption of fruit and vegetables among older adults. J. Nutr. Elder. 24:5-21.

Schlettwein-Gsell, D. 1992. Nutrition and the quality of life: A measure for the outcome of nutritional intervention? Amer. J. Clin. Nutr. 55:1263S-1266S.

Shepherd, R. and G. Towler. 2007. Nutrition knowledge, attitudes and fat intake: Application of the theory or reasoned action. J. Hum. Nutr. Diet. 20: 159-169.

Sjoberg, S., K. Kim, and M. Reicks. 2004. Applying the theory of planned behavior to fruit and vegetable consumption by older adults. J. Nutr. Gerontol. Geriatrics 23:35-46.

Sommerfeld, A., A.L. McFarland, T.M. Waliczek, and J.M. Zajicek. 2010a. Growing minds: Evaluating the relationship between gardening and fruit and vegetable consumption in older adults. HortTechnology 20:711-717.

Sommerfeld, A., T.M. Waliczek, and J.M. Zajicek. 2010b. Growing minds: Evaluating the effect of gardening on quality of life and physical activity level of older adults. HortTechnology 20:705-710.

Vitolins, M.Z., J.A. Tooze, S.L. Golden, T.A. Arcury, R.A. Bell, C. Davis, R.F. Devellis, and S.A. Quandt. 2007. Older adults in the rural south are not meeting healthful eating guidelines. J. Amer. Dietetic Assn. 107:265-272.

Wang, Y., M.A. Beydoun, L. Liang, B. Caballero, and S.K. Kumanyika. 2008. Will all Americans become overweight or obese? Estimating the progression and cost of the US obesity epidemic. Obesity (Silver Spring) 16:2323-2330.

Wardle, J., K. Parmenter, and J. Waller. 2000. Nutrition knowledge and food intake. Appetite 34:269-275. 